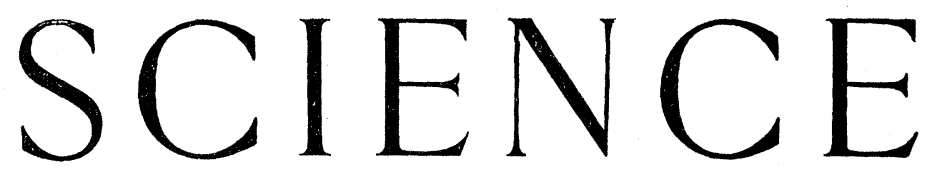

NEW YORK, SEPTEMBER 16, 1892.

\section{DANGER FROM THE POPULAR MISUSE OF QUININE.}

BY W. THORNTON PARKER, M.D

A RECENT editorial in the Medical News of April 2, 1892, concerning deaths from cocaine, may well be noticed in connection with the investigation of dangers from the popular misuse of quinine. "I have never seen it," ergo "No man's experience, however wide, can cover all the possibilities of disease and accident. It may be well and wise for one to say, 'I have not seen it,' when the possibility or likelihood of this or that pathologic or toxic accident is under discussion; but it is never wise and nerer well because of the perhaps limitation of one's own experience to deny the reality of occurrences vouched for by competent observers, and not in themselves incredible."

A recent item in one of the daily journals has prompted me to say a word against the misuse of the popular remedy known as quinine. The item referred to states that a sea-captain, sailing his craft too near a sunken ledge, was warned to give the dangerous quarter a wide berth. He replied, by yelling out at his adviser, "You go straight to hell; I am sailing this craft where I - please." The vessel was wrecked, and the insurance money refused on the ground that the captain wilfully destroyed his vessel. This the defence emphatically denied. In explanation of his extraordinary language, the captain stated that he had been suffering from malaria, and had taken large doses of quinine for relief, and had become so much "influenced" by its action that really he did not know what he was saying or doing.

Few, if any medicines, enter so largely and generally into popular use as quinine. Throughout the world we find it almost everywhere for sale; it can be purchased in any quantity by anybody, and used as the purchaser may think best, in larger or smaller doses, at intervals, or continually. Few seem to understand its poisonous action, or even suspect that its continual use can result in any special injury to the system. It is prescribed by all sorts and conditions of men, women, and children. Ruse, in his excellent text-book of medical jurisprudence, defines a poison as "a substance which, when introduced into the body by swallowing or by any other method, occasions disease or death; and this as an ordinary result in a state of health, and not by a mechanical action. It must be as an ordinary result; a substance, for example, which affects one person injuriously through idiosyncrasy, is not to be called poison. Again it must be in the healthy system, as is well known, many diseases render the system extremely susceptible to impressions by external agents, e. g., in gastritis, the blandest substance, eren water, may excite vomiting."

The action of the malarial poison upon the system is of such a nature that many would claim that any abnormal nervous impression would be more likely to have its origin in the malarial poison than in the quinine, which is given with a view to neutralizing that poison. We know of so many diseases following the inception of the malarial germs that any attack upon quinine, as a poisonous remedy, may reasonably expect prompt resentment. Ringer states, that "large doses produce severe frontal headache with dull, heavy, tensive. and sometimes agonizing pains. While these symptoms Jast, and, indeed, generally before they appear, the face is flushed, the eyes suffused, and the expression is dull and stupid. Even small doses in persons very susceptible to the action, of this medicine will produce some of the foregoing symp. toms, especially the headache and mental disturbance. Many of thest symptoms are, no doubt, due to the action of quinia on the brain. In toxic doses it excites convulsions. Chirone and Curc find that the removal of the motor centres of the brain prevents these convulsions; and, if the central hemisphere is remored on one side, the convulsions are unilateral. Albertoni, on the other hand, finds that quinia will induce convulsions when the central hemisphere or the cortical motor centres are removed." Dr. Bartholow states, that "In full medicinal doses, as the quinia accumulates in the brain, a sense of fullness in the head, constriction of the forehead, tinnitus aurium, more or less giddiness, eren decided vertigo, maý be produced. In actually toxic doses all of the above symptoms have been intensified. There are intense headache with constriction of the forehead, dimness of vision, or complete blindness, deafness, delirium, or coma, dilated pupils, weak, fluttering pulse, irregular and shallow respiration, convulsions, and finally collapse and death." Dr. Wood states, that "The minimum fatal dose of quinine is not known, but it must be large, and probably raries very much." Brown-Sequard states, that "In epileptics the attacks are rendered decidedly more frequent by the cinchona alkaloids." Dr. Wood is of the opinion, also, that "In large doses quinia, without doubt, abolishes the functions of the cerebrum."

From the foregoing we have evidence to demonstrate that quinia is too dangerous a remedy to be prescribed recklessly by medical men, and that its popular use by people ignorant of its action should be condemned and, if possible, prevented. In our own practice we have known of four cases where moderate doses continued even for two or three days would produce serious cerebral disturbance amounting to almost homicidal mania. There are very many cases in every community where the use of quinine will affect the nervous system of patients in a serious manner. One patient, after using ten grains, did not know whether it was morning or evening, and was bewildered in finding his way home. Another complained to me that he could not take quinine without feeling cross and out of sorts for a week afterwards. Still another, a very peaceful man naturally, stated that the use of quinine for a day or so made him quarrelsome and pugilistic, and he feared that under its influence he might commit some act which might bring him into serious trouble. Supposing that a lawyer should offer in defence of his client the statement that, acting under the advice of his physician, the patient had been taking large doses of quinine for several days, and in a paroxysm of rage, while under the influence of the drug, he had committed homicide, would this man in equity be responsible for his deed ? That quinine is a dangerous drug with many there can be no doubt, that it is universally dangerous there may be some question. It seems to me but just, under the circumstances, that it should be rated as a poison. The study of the action of quinine, from a medico-legal standpoint, is one, therefore, not without interest.

\section{POPULAR EREORS ABOUT WILD ANIMALS.}

BY THEODORE B. COMSTOCK.

IN the issue of the Popular Science Monthly for September, 1892 , at page 719 , is the following item under "Notes":-

"A novel view of the puma, or panther, as it is commonly called, is taken by Mr. W. H. Hudson, in his 'Naturalist in La Plata,' who insists that it never attacks men except in self-defence. In the pampas, where it is common, the gaucho confidently sleeps on the ground, although he knows that pumas are close by; and it is said that a child may sleep on the plain unprotected in equal security."

There are many popular notions concerning the danger from wild animals which everyone who has travelled out of the beaten 
paths has come to know as groundless. The puma, or American panther, and its South American representative, the jaguar, are not regarded by experienced hunters and naturalists as animals to be feared, excepting under circumstances which leave no avenue of escape open to the beast. The writer has repeatedly observed this fact in connection with the puma in this country, with the jaguar in the forests of the Amazon, and with various other wild animals, in both regions, which are terrible antagonists when brought to bay by wounds or other events demanding defence of self or young. The puma plays like a cat about the lonely traveller on foot or snow-shoes in the Rocky Mountains, and the curiosity of the jaguar brings him nightly to the camps of voyagers along the Brazilian rivers. I have often in that region been disturbed in sleep by such prowlers, who would rush suddenly off upon the slightest movement of my body; and upon numerous occasions in the morning fresh tracks in the sand all around our blankets would be visible, many times without our being awakened by the movements of the animals.

Mr. Hudson's remarks regarding the fearlessness of the natives in La Plata do not, however, agree with my own observations of the average Amazonian dwellers. As an instance, one night in $18 \%$, at the Cachociras (waterfalls) de Maroim upon the Tocantins River, some 200 miles above the city of Pará, we encamped in the forest at the edge of the river, contrary to our usual custom of selecting a sandy island. Some in hammocks, others with blankets spread upon the ground, we North-Americans all slept soundly, notwithstanding that a rock cavern with well-gnawed bones and other signs of jaguar occupancy lay within 200 feet of the camp. I did awake once and saw the glaring eyes of a huge jaguar, as I supposed, within a few feet of my hammock. Next morning the tracks were evident in this particular spot, as well as many others all around camp, which were not there when we lay down at night. But the natives! Every mother's son of them uttered that night fervent prayers for protection, and sought rest in the tree-tops, swinging their hammocks from limbs hanging far out over the water, at the same time cautioning us of the great danger to be feared from vicious attacks of the tigers. This is only one of a number of similar instances, and not a little experience with the puma and with bears of various kinds (including the cinnamon and grizzly) and other animais of reputation for unbridled ferocity, has brought me to the same conclusion regarding them. The writer called attention to the harmless nature of some supposed dangerous feres as early as 1873-74 in articles in the American Naturatist upon "The Scientific Value of the Yellowstone Park."

Venomous reptiles and insects, as the rattlesnake, "Gila Monster," tarantula, scorpion, centipede, etc., have reputations beyond their deserts for blood-thirstiness. Notwithstanding the numerous authentic cases of poisoning by them, I have yet to learn of one which cannot be fairly regarded as the derrier resort of the animal in a defensive attitude. Give any one of these creatures a reasonable (to their notion) chance of escape and they will avail themselves of it in preference to attack. One may come upon them suddenly, and unconsciously put them in a position from which no escape is open; but, if they are let alone or given a free field, they will always avail themselves of it. I remember the case of a rattlesnake in Texas, which we had surrounded and which was menaced by clubs upon all sides. He ran for dear life, striving his best to pass the gaps between each pair of enemies, until, baffled at every point, he suddenly turned upon the writer for an attack. As soon, however, as this manouvre had opened a passage-way in one direction, he darted off and was again caught only with great difficulty. So, in Indian Territory, among the Wichita Mountains, where the rattlesnakes are akin to boas in size and hideousness, they are wofully sluggish. I have encountered them there among the rocks and in the tall grass, with the sickening rattle sounding long enough to get far from harm before the dangerous thrust was made. My horse has almost stepped upon them in such situations in that region, as well as in Wyoming, Texas, Arizona, and elsewhere, without further result than a scampering off of the snake. Much as the boa constrictor is dreaded in Brazil, cases are exceedingly rare of the exercise of its undoubted power over humanity.
The alligator, with all his ability to devour, is an arrant coward, and we often bathed in the tropical rivers where they were disporting themselves not far away. The natives there claim that none but drunken men are in danger from their attacks.

Hunger, endangerment of life, excessice fear of man with no means of escape, and a sudden surprise are all effective in bringing up every means of defence. The real danger from association with many of these creatures is the liability to meet them unawares, or to suddenly place them on the defensive through the unconscious movements of sleep. The more sluggish or the smaller the animal, the greater is this risk.

In Arizona the bite of a certain small species of skunk is very much dreaded, owing to the belief that hydrophobia is a probable result. There is almost no danger from this source, nor from the vile excretions of other species of polecat, if one does not directly attack them; but from their unfortunate sociability in this region, a sleeping person may suddenly throw out his hand when disturbed, without awakening. In nine cases out of ten this will drive off the intruder, who will rarely return. Occasionally, however, such an act may hit the animal, when he will bite as be flees. Very few cases of this kind have been reported. I have frequently discovered innumerable tracks of these animals about my cot of a morning when camping in sandy tracts, and sometimes have seen them moving about. A movement of the arm is always enough to send them post-haste to cover at a distance. Persons lying on blankets on the ground need more caution, as these "essence peddlers" will sometimes occupy such beds on cold nights.

Skunks are extremely abundant for several weeks in autumn in this region. Last year four of them entered the university itself, and at one point in the Baboquivon Mountains as many as thirty were killed near our cabin in two or three days. They would come up to the doors at midday, and as many as seven at one time were seen on moonlight nights within shooting distance.

These pests have again made their appearance this month. There seem to be four kinds of them, varying materially in "scentability" from the inodorous little biter to the one which is the very quintessence of malodorousness, and in color from a light gray to a dense black with white tail. Somehow or other, one of each kind inhabited a cosy nook beneath the writer's office last fall. The little gray one was particularly fond of intruding into my bed-room until the shot-gun was called into requisition.

Tucson, Arizona, Sept. 5.

\section{CONCERNING THE AERATION OF MILK.}

BY C. S. PLUMB, DIRECTOR AGRICULTURAL EXPERIMENT STATION OF INDIANA.

MUCH advance has been made in our knowledge of dairying of late years, and especially in America has there been much attention devoted to problems affecting the industry, which has resulted in remarkable progress. Some of the American agricultural experiment stations have made themselves best known by the dairy investigations they have conducted.

Among these subjects of study has been that of the influence of aeration upon milk. Milk fresh from the cow, that was aerated and suddenly reduced in temperature at the same time, it was claimed, would remain sweet longer than milk not so treated set under similar conditions. Within a comparatively short time aerating machines have been placed on the market, that are credited with removing disagreeable odors and retarding acidity of milk.

Bulletin 27 of the Vermont Experiment Station. for January, 1892, states that the "aerator gave good satisfaction" when in use at that institution. At the Cornell University Experiment Station the aeration and cooling of milk were studied by Professor H. H. Wing, and the results published in Bulletin 39, for July, 1892. In this it is shown that the Champion aerator will cool 225 to 250 pounds of milk per hour down to about $60^{\circ} \mathrm{F}$. Milk passed over the Champion was, on an average, perceptibly sour in fifty hours after setting; that aerated on the Star machine was soir in fifty-one hours; while milk aerated with the Powell machine 